\title{
A parametric study based on spectral fatigue analysis for 170k LNGC
}

\author{
Tae-Yoon Park ${ }^{1}$, Chang-Doo Jang ${ }^{1}$, Yong-Suk $\mathrm{Suh}^{2}$ and Bong-Jae Kim² \\ ${ }^{I}$ Department of Naval Architecture \& Ocean Engineering, Seoul National University, South Korea \\ ${ }^{2}$ Samsung Heavy Industries, Kyungnam, South Korea
}

\begin{abstract}
The Spectral Fatigue Analysis is representative fatigue life assessment method for vessels. This Analysis is performed generally for the whole vessel and many assessment sites. The spectral fatigue analysis is performed through the process of hydrodynamic response analysis, global structural analysis, local structural analysis and calculation of fatigue damage. In these processes, fatigue damage is affected by many variables. The representative variables are $S-N$ curve data, wave scatter data, wave spectrum, bandwidth effect and etc. In this paper, the effects of these variables to the fatigue damage are analyzed through the spectral fatigue analysis for $170 \mathrm{k} L \mathrm{NGC}$.
\end{abstract}

KEY WORDS: Spectral Fatigue Analysis; Fatigue Life Prediction; Parametric Study; Design Variable.

\section{NOMENCLATURE}

$\begin{array}{ll}N & \text { fatigue life } \\ \log \bar{a} & \text { intercept of the } \log N \text { axis } \\ m & \text { inverse negative slope of the S-N curve } \\ S_{\eta} & \text { wave energy spectrum } \\ H_{s} & \text { significant wave height } \\ T_{z} & \text { zero-crossing period } \\ \omega & \text { wave frequency } \\ \omega_{p} & \text { peak wave frequency } \\ \varepsilon & \text { bandwidth parameter } \\ m_{n} & \text { moment of spectrum }\end{array}$

\section{INTRODUCTION}

The fatigue fracture is a primary cause of the fracture of offshore structures and vessels. The fatigue fracture is a phenomenon which is occurred by cumulative damage due to fluctuating loads. The fatigue life is composed with the fatigue crack initiation life and fatigue crack propagation life. The fatigue life of vessels is assessed by using Miner's linear cumulative law(Miner, 1945).

Corresponding author: Tae-Yoon Park

e-mail:parkty55@snu.ac.kr
The representative fatigue life assessment methods are simplified fatigue life assessment method and spectral fatigue life assessment method. (DNV, 2008; ABS, 2006; Lloyd, 2002; KR, 2010) In the case of simplified fatigue life assessment method, the dominant loads which determine the stress range of the assessment sites are calculated by empirical formulas. The specific characteristic of the simplified method is assumption of the long-term distribution of stress ranges. The long-term distributions are assumed by using Weibull distribution. Because of this assumption, we could not consider the effect of variables which affect the long-term distribution of the stress ranges in the simplified method.

The spectral fatigue analysis method is used for fatigue life assessment for vessels generally. In the case of spectral fatigue analysis, the motion RAO about unit amplitude waves for specific heading angle and wave frequency are calculated and load transfer function is calculated by using the motion RAO. Then, the global structural analysis using load transfer function and global FE model is performed. The result of global structural analysis provides boundary displacements of local FE model. The next step is calculation of stress transfer function at the hot spot and final fatigue damage using this stress transfer function, wave energy spectrum, wave scatter data and S-N curve. In the process of the spectral fatigue analysis, the fatigue damage is affected by several variables like S-N curve, wave scatter data, wave spectrum, bandwidth effect and etc. In this paper, through the spectral fatigue analysis for $170 \mathrm{k}$ LNGC, the effects of these variables to the fatigue damage are analyzed. 


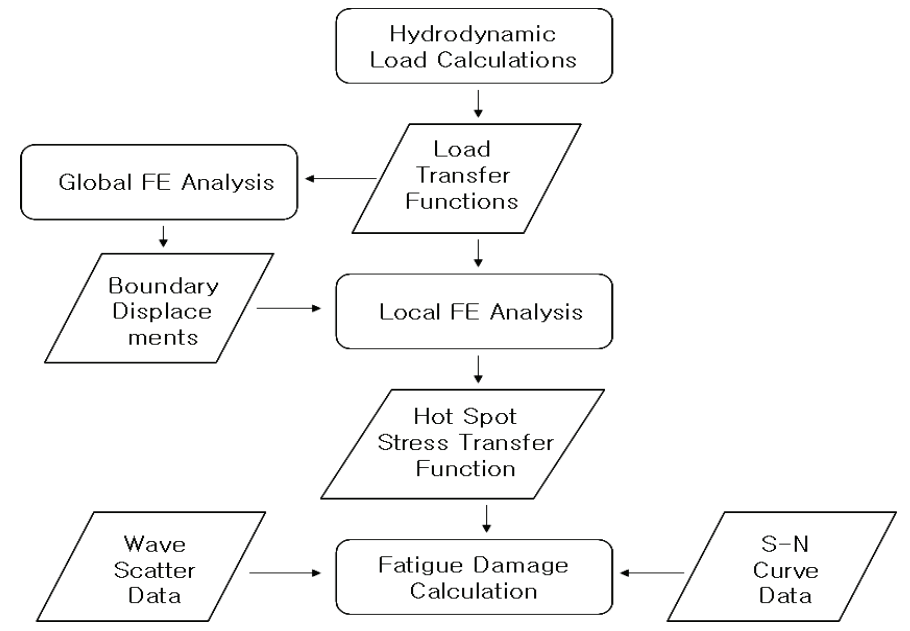

Fig. 1 Flowchart of Spectral Fatigue Analysis.

\section{DESIGN VARIABLES}

\section{S-N curve}

S-N curve is necessary data when we assess fatigue life of structure by using Miner's linear cumulative law. The S-N curve is based on experimental results and different for the each material. The S-N curves used in fatigue life assessment of hull structures are generally suggested by classification societies. The representative S-N curves are ABS S-N curve and DNV S-N curve. Their S-N curves are as follows.

$$
\log N=\log \bar{a}-m \log \Delta \sigma
$$

Table 1 ABS S-N Curve.

\begin{tabular}{|c|c|c|c|c|}
\hline \multirow{2}{*}{ Class } & \multicolumn{2}{|c|}{$N \leq 10^{7}$} & \multicolumn{2}{c|}{$N>10^{7}$} \\
\cline { 2 - 5 } & $\log \bar{a}$ & $m$ & $\log \bar{a}$ & $m$ \\
\hline B & 15.006 & 4 & 19.009 & 6 \\
\hline C & 13.626 & 3.5 & 17.412 & 5.5 \\
\hline D & 12.182 & 3 & 15.627 & 5 \\
\hline E & 12.015 & 3 & 15.362 & 5 \\
\hline F & 11.800 & 3 & 14.999 & 5 \\
\hline F2 & 11.634 & 3 & 14.722 & 5 \\
\hline G & 11.394 & 3 & 14.330 & 5 \\
\hline W & 11.197 & 3 & 14.007 & 5 \\
\hline
\end{tabular}

Table 2 DNV S-N Curve.

\begin{tabular}{|c|c|c|c|c|}
\hline \multirow{2}{*}{ Class } & \multicolumn{2}{|c|}{$N \leq 10^{7}$} & \multicolumn{2}{c|}{$N>10^{7}$} \\
\cline { 2 - 5 } & $\log \bar{a}$ & $m$ & $\log \bar{a}$ & $m$ \\
\hline I & 12.164 & 3 & 15.606 & 5 \\
\hline III & 15.117 & 4 & 17.146 & 5 \\
\hline IV & 12.436 & 3 & 12.436 & 3 \\
\hline
\end{tabular}

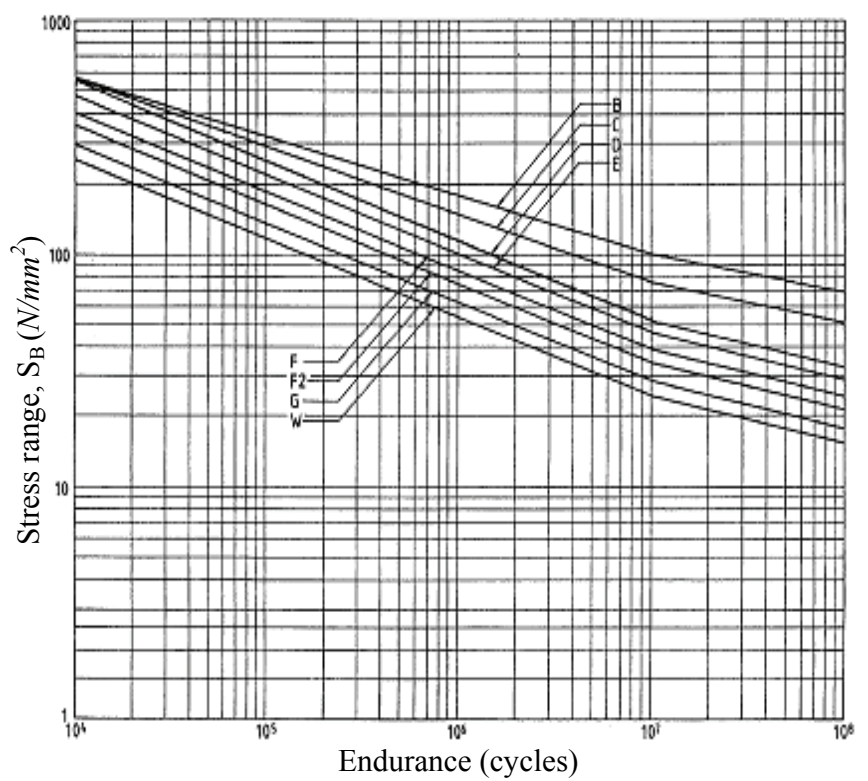

Fig. 2 ABS S-N Curve.

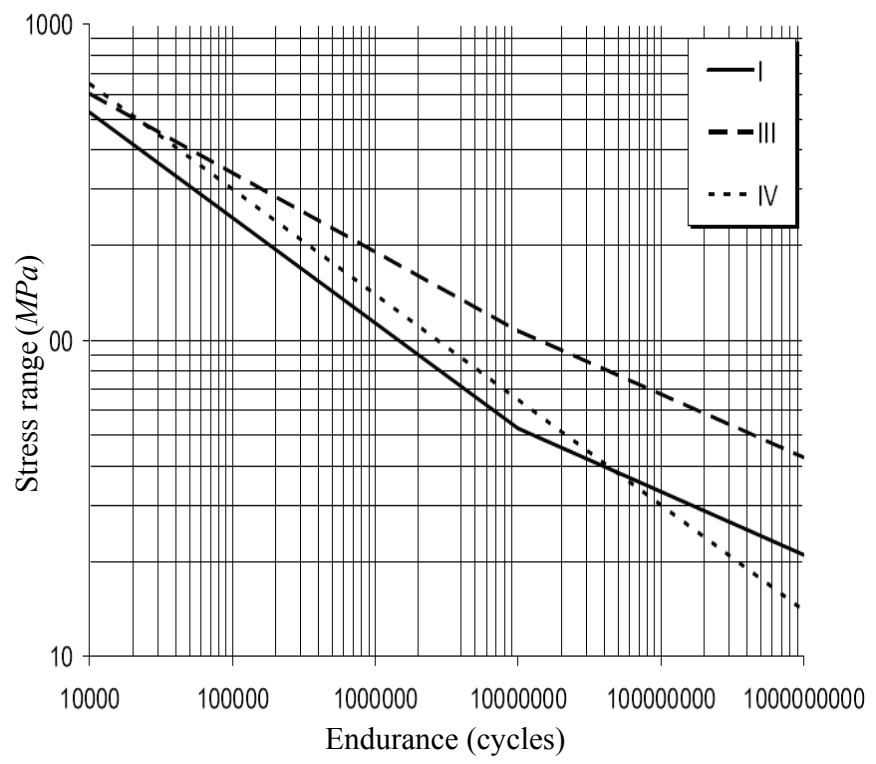

Fig. 3 DNV S-N Curve.

In this paper, we used the S-N curves which are DNV US-I, DNV US-III, ABS C and ABS E for parametric study. In general, these S-N curves are often used for fatigue analysis of hull structure.

\section{Wave scatter data}

The wave scatter data are composed with revelation probabilities according to significant wave height and zerocrossing period. The wave scatter data are generally suggested by classification societies and international research institutes. The representative wave scatter data are IACS North Atlantic wave scatter data (IACS NA), ABS unrestricted wave scatter data (ABS unres.), DNV worldwide wave scatter data (DNV WW), WALDEN wave scatter data (WALDEN) and etc. These wave scatter data are generated 
by measurements of global oceans like the North Atlantic. measurements of local oceans like Gulfs, Haltenbanken and Another representative wave scatter data are generated by etc. The BMT wave scatter data are representative.

\begin{tabular}{|c|c|c|c|c|c|c|c|c|c|c|c|c|c|c|c|c|c|}
\hline $\mathrm{Tz}(\mathrm{s})$ & 3.5 & 4.5 & 5.5 & 6.5 & 7.5 & 8.5 & 9.5 & 10.5 & 11.5 & 12.5 & 13.5 & 14.5 & 15.5 & 16.5 & 17.5 & 18.5 & Sum \\
\hline \multicolumn{18}{|l|}{$\begin{array}{l}\mathrm{Hs} \\
\text { (m) }\end{array}$} \\
\hline 0.5 & 1.3 & 133.7 & 865.6 & 1186.0 & 634.2 & 186.3 & 36.9 & 5.6 & 0.7 & 0.1 & 0 & 0 & 0 & 0 & 0 & 0 & 3050 \\
\hline 1.5 & 0 & 29.3 & 986.0 & 4976.0 & 7738.0 & 5569.7 & 2375.7 & 703.5 & 160.7 & 30.5 & 5.1 & 0.8 & 0.1 & 0 & 0 & 0 & 22575 \\
\hline 2.5 & 0 & 2.2 & 197.5 & 2158.8 & 6230.0 & 7449.5 & 4860.4 & 2066.0 & 644.5 & 160.2 & 33.7 & 6.3 & 1.1 & 0.2 & 0 & 0 & 23810 \\
\hline 3.5 & 0 & 0.2 & 34.9 & 695.5 & 3226.5 & 5675.0 & 5099.1 & 2838.0 & 1114.4 & 337.7 & 84.3 & 18.2 & 3.5 & 0.6 & 0.1 & 0 & 19128 \\
\hline 4.5 & 0 & 0 & 6.0 & 196.1 & 1354.3 & 3288.5 & 3857.5 & 2685.5 & 1275.2 & 455.1 & 130.9 & 31.9 & 6.9 & 1.3 & 0.2 & 0 & 13289 \\
\hline 5.5 & 0 & 0 & 1.0 & 51.0 & 498.4 & 1602.9 & 2372.7 & 2008.3 & 1126.0 & 463.6 & 150.9 & 41.0 & 9.7 & 2.1 & 0.4 & 0.1 & 8328 \\
\hline 6.5 & 0 & 0 & 0.2 & 12.6 & 167.0 & 690.3 & 1257.9 & 1268.6 & 825.9 & 386.8 & 140.8 & 42.2 & 10.9 & 2.5 & 0.5 & 0.1 & 4806 \\
\hline 7.5 & 0 & 0 & 0 & 3.0 & 52.1 & 270.1 & 594.4 & 703.2 & 524.9 & 276.7 & 111.7 & 36.7 & 10.2 & 2.5 & 0.6 & 0.1 & 2586 \\
\hline 8.5 & 0 & 0 & 0 & 0.7 & 15.4 & 97.9 & 255.9 & 350.6 & 296.9 & 174.6 & 77.6 & 27.7 & 8.4 & 2.2 & 0.5 & 0.1 & 1309 \\
\hline 9.5 & 0 & 0 & 0 & 0.2 & 4.3 & 33.2 & 101.9 & 159.9 & 152.2 & 99.2 & 48.3 & 18.7 & 6.1 & 1.7 & 0.4 & 0.1 & 626 \\
\hline 10.5 & 0 & 0 & 0 & 0 & 1.2 & 10.7 & 37.9 & 67.5 & 71.7 & 51.5 & 27.3 & 11.4 & 4.0 & 1.2 & 0.3 & 0.1 & 285 \\
\hline 11.5 & 0 & 0 & 0 & 0 & 0.3 & 3.3 & 13.3 & 26.6 & 31.4 & 24.7 & 14.2 & 6.4 & 2.4 & 0.7 & 0.2 & 0.1 & 124 \\
\hline 12.5 & 0 & 0 & 0 & 0 & 0.1 & 1.0 & 4.4 & 9.9 & 12.8 & 11.0 & 6.8 & 3.3 & 1.3 & 0.4 & 0.1 & 0 & 51 \\
\hline 13.5 & 0 & 0 & 0 & 0 & 0 & 0.3 & 1.4 & 3.5 & 5.0 & 4.6 & 3.1 & 1.6 & 0.7 & 0.2 & 0.1 & 0 & 21 \\
\hline 14.5 & 0 & 0 & 0 & 0 & 0 & 0.1 & 0.4 & 1.2 & 1.8 & 1.8 & 1.3 & 0.7 & 0.3 & 0.1 & 0 & 0 & 8 \\
\hline 15.5 & 0 & 0 & 0 & 0 & 0 & 0 & 0.1 & 0.4 & 0.6 & 0.7 & 0.5 & 0.3 & 0.1 & 0.1 & 0 & 0 & 3 \\
\hline 16.5 & 0 & 0 & 0 & 0 & 0 & 0 & 0 & 0.1 & 0.2 & 0.2 & 0.2 & 0.1 & 0.1 & 0 & 0 & 0 & 1 \\
\hline Sum & 1 & 165 & 2091 & 9280 & 19922 & 24879 & 20870 & 12898 & 6245 & 2479 & 837 & 247 & 66 & 16 & 3 & 1 & 100000 \\
\hline
\end{tabular}

Fig. 4 IACS North Atlantic Wave Scatter Data.

\begin{tabular}{|l|rrrrrrrrrrrrrrrrr|}
\hline $\mathrm{Tz}(\mathrm{s})$ & 3.5 & 4.5 & 5.5 & 6.5 & 7.5 & 8.5 & 9.5 & 10.5 & 11.5 & 12.5 & 13.5 & 14.5 & 15.5 & 16.5 & 17.5 & Sum \\
\hline $\mathrm{Hs}$ & & & & & & & & & & & & & & & & \\
$\mathrm{(m)}$ & & & & & & & & & & & & & & & & \\
1.0 & 311 & 2734 & 6402 & 7132 & 5071 & 2711 & 1202 & 470 & 169 & 57 & 19 & 6 & 2 & 1 & 0 & 26287 \\
2.0 & 20 & 764 & 4453 & 8841 & 9045 & 6020 & 3000 & 1225 & 435 & 140 & 42 & 12 & 3 & 1 & 0 & 34001 \\
3.0 & 0 & 57 & 902 & 3474 & 5549 & 4973 & 3004 & 1377 & 518 & 169 & 50 & 14 & 4 & 1 & 0 & 20092 \\
4.0 & 0 & 4 & 150 & 1007 & 2401 & 2881 & 2156 & 1154 & 485 & 171 & 53 & 15 & 4 & 1 & 0 & 10482 \\
5.0 & 0 & 0 & 25 & 258 & 859 & 1338 & 1230 & 776 & 372 & 146 & 49 & 15 & 4 & 1 & 0 & 5073 \\
6.0 & 0 & 0 & 4 & 63 & 277 & 540 & 597 & 440 & 240 & 105 & 39 & 13 & 4 & 1 & 0 & 2323 \\
7.0 & 0 & 0 & 1 & 15 & 84 & 198 & 258 & 219 & 136 & 66 & 27 & 10 & 3 & 1 & 0 & 1018 \\
8.0 & 0 & 0 & 0 & 4 & 25 & 69 & 103 & 99 & 69 & 37 & 17 & 6 & 2 & 1 & 0 & 432 \\
9.0 & 0 & 0 & 0 & 1 & 7 & 23 & 39 & 42 & 32 & 19 & 9 & 4 & 1 & 1 & 0 & 178 \\
10.0 & 0 & 0 & 0 & 0 & 2 & 7 & 14 & 16 & 14 & 9 & 5 & 2 & 1 & 0 & 0 & 70 \\
11.0 & 0 & 0 & 0 & 0 & 1 & 2 & 5 & 6 & 6 & 4 & 2 & 1 & 1 & 0 & 0 & 28 \\
12.0 & 0 & 0 & 0 & 0 & 0 & 1 & 2 & 2 & 2 & 2 & 1 & 1 & 0 & 0 & 0 & 11 \\
13.0 & 0 & 0 & 0 & 0 & 0 & 0 & 1 & 1 & 1 & 1 & 0 & 0 & 0 & 0 & 0 & 4 \\
14.0 & 0 & 0 & 0 & 0 & 0 & 0 & 0 & 0 & 1 & 0 & 0 & 0 & 0 & 0 & 0 & 1 \\
& & & & & & & & & & & & & & & & 100000 \\
$\mathrm{Sum}$ & 331 & 3559 & 11937 & 20 & 795 & 23321 & 18763 & 11611 & 5827 & 2480 & 926 & 313 & 99 & 29 & 9 & 0 & 10 \\
\hline
\end{tabular}

Fig. 5 DNV Worldwide Wave Scatter Data. 
In the spectral fatigue analysis, the wave scatter data are extremely dominant design variable. Therefore, in this paper, we used the wave scatter data which are IACS NA, ABS unres., DNV WW and WALDEN for parametric study.

\section{Wave spectrum}

The representative wave energy spectrums are PiersonMoskowitz wave spectrum and JONSWAP wave spectrum. (Almar, 1985). The spectrums are as follows.

Pierson - Moskowitz wave spectrum :

$S_{\eta}\left(\omega \mid H_{s}, T_{z}\right)=\frac{H_{s}{ }^{2}}{4 \pi}\left(\frac{2 \pi}{T_{z}}\right)^{4} \omega^{-5} \exp \left[-\frac{1}{\pi}\left(\frac{2 \pi}{T_{z}}\right)^{4} \omega^{-4}\right]$

ONSWAP wave spectrum :

$S_{\eta}\left(\omega \mid H_{s}, T_{z}\right)=a g^{2} \omega^{-5} \exp \left[-\frac{5}{4}\left(\frac{\omega}{\omega_{p}}\right)^{-4}\right] \gamma \gamma^{\exp \left(-\frac{\left(\frac{\omega}{\omega_{p}}-1\right)^{2}}{2 \omega^{2}}\right)}$

The Pierson-Moskowitz wave spectrum is generally used for spectral fatigue analysis of usual vessels because the Pierson-Moskowitz wave spectrum is used for fully developed sea. On the other hands, the JONSWAP wave spectrum is used for non-fully developed sea. In this paper, we used these two wave spectrums for the parametric study.

\section{Bandwidth effect}

In the spectral fatigue analysis, the short-term distribution of stress ranges is generally assumed to be the Rayleigh distribution, because the Rayleigh distribution is able to be easily calculated with Gamma function.

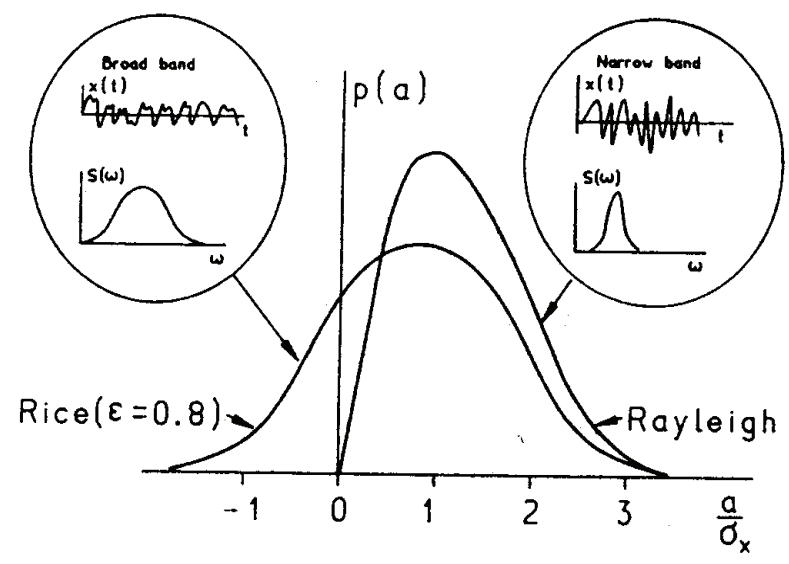

Fig. 6 Rice distribution and Rayleigh distribution.

The Rayleigh distribution is suitable for the narrowbanded data which has zero bandwidth parameter $(\varepsilon=0)$.

$$
\varepsilon=\left(1-\frac{m_{2}^{2}}{m_{0} \cdot m_{4}}\right)^{\frac{1}{2}}
$$

But the short-term distribution of stress ranges has not zero bandwidth parameter practically. Therefore, some errors are occurred in the calculation when this assumption used. In order to correct these errors, the rainflow bandwidth correction factor is used.

$$
\begin{aligned}
& \lambda_{i j}=a+(1-a)\left(1-\varepsilon_{i j}\right)^{b} \\
& a=0.926-0.033 m, b=1.587 m-2.323
\end{aligned}
$$

In this paper, we analyzed the results of difference whether applying this correction factor or not in the parametric study.

\section{SPECTRAL FATIGUE ANALYSIS FOR 170K LNGC}

In this paper, the spectral fatigue analysis was performed for $170 k$ LNGC. The Fig. 7 is panel elements for calculation of hydrodynamic response. The hydrodynamic analysis was performed by WASIM in the DNV SESAM Program. The range of wave frequency is from $0.2 \mathrm{rad} / \mathrm{s}$ to $1.8 \mathrm{rad} / \mathrm{s}$, and the range of heading angle is from $0^{\circ}$ to $330^{\circ}$ and the increment is $30^{\circ}$.

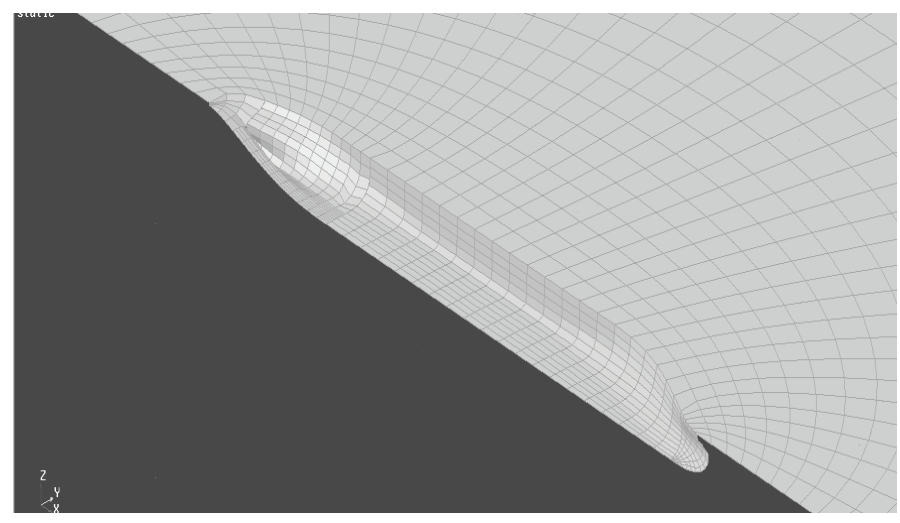

Fig. 7 Panel Elements for Calculation of Hydrodynamic Response.

The Fig. 8 is global FE model for global structural analysis. The global structural analysis was performed by SESTRA in the DNV SESAM Program.

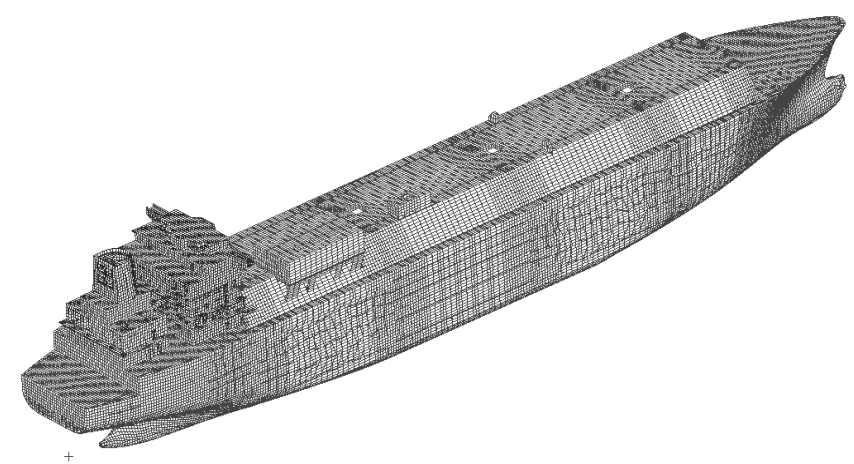

Fig. 8 170k LNGC Global FE Model. 
The Fig. 9 is local fine FE model for local structural analysis. The assessment sites are upper hopper knuckle and lower hopper knuckle.

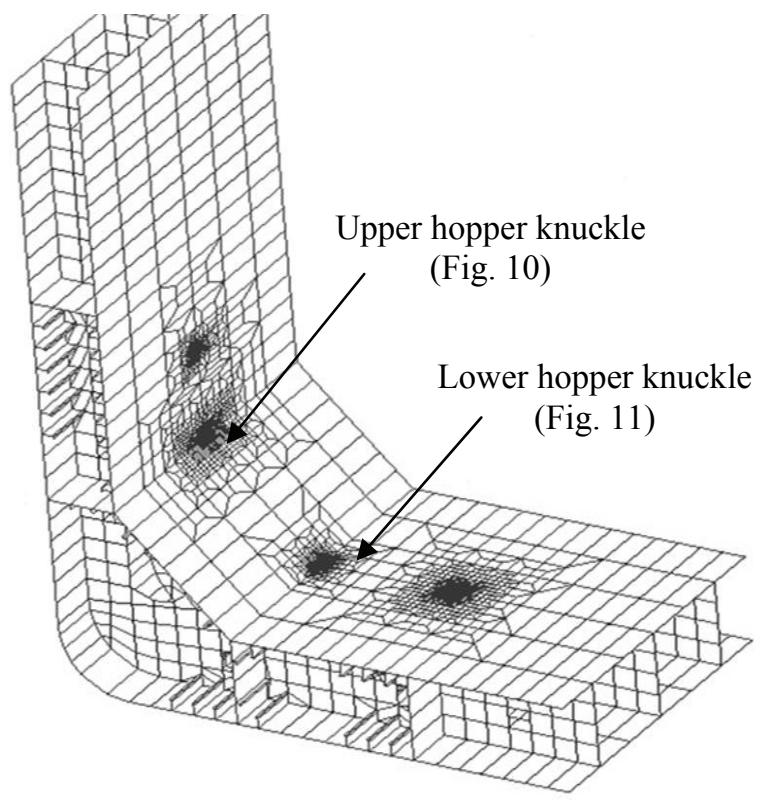

Fig. 9 Local FE Model of Lower Hopper Knuckle.

The fatigue damages were calculated for 4 elements in the each hotspot. These elements are as follows.

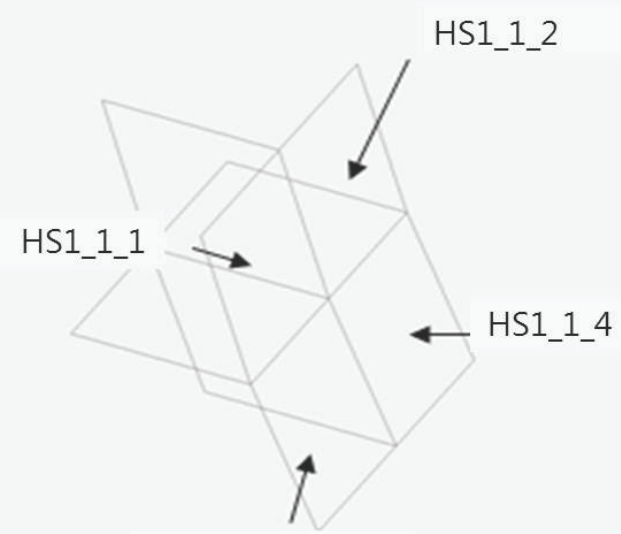

HS1_1_3

Fig. 10 Hotspot of Upper Hopper Knuckle.

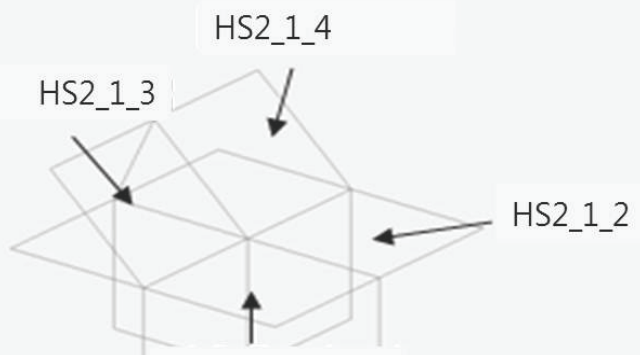

HS2_1_1

Fig. 11 Hotspot of Lower Hopper Knuckle.
The calculation of fatigue damage was performed by STOFAT in the DNV SESAM Program.

\section{RESULTS OF PARAMETRIC STUDY}

\section{S-N curve}

Table 3 Fatigue Damage due to S-N Curve (1).

\begin{tabular}{|c|c|c|c|c|}
\hline & HS & HS & HS & HS \\
& $1 \_1 \_1$ & $1 \_1 \_2$ & $1 \_1 \_3$ & $1 \_1 \_4$ \\
\hline DNV US-I & 0.4021 & 0.3648 & 0.2817 & 0.2474 \\
\hline $\begin{array}{c}\text { DNV US- } \\
\text { III }\end{array}$ & 0.0184 & 0.0163 & 0.0118 & 0.0101 \\
\hline ABS C & 0.0698 & 0.0618 & 0.0451 & 0.0383 \\
\hline ABS E & 0.6221 & 0.5669 & 0.4420 & 0.3902 \\
\hline
\end{tabular}

Table 4 Fatigue Damage due to S-N Curve (2).

\begin{tabular}{|c|c|c|c|c|}
\hline S-N Curve & HS & HS & HS & HS \\
& 2_1 & 2_1_2 & 2_1_3 & 2_1_4 \\
\hline $\begin{array}{c}\text { DNV US-I } \\
\text { DNV US- } \\
\text { III }\end{array}$ & 0.0962 & 0.0873 & 0.1937 & 0.1674 \\
\hline ABS C & 0.0122 & 0.0109 & 0.0285 & 0.0239 \\
\hline ABS E & 0.1574 & 0.1433 & 0.3082 & 0.2679 \\
\hline
\end{tabular}

\section{Wave scatter data}

Table 5 Fatigue Damage due to Wave Scatter Data (1).

\begin{tabular}{|c|c|c|c|c|}
\hline $\begin{array}{l}\text { Wave } \\
\text { Scatter } \\
\text { Data }\end{array}$ & $\begin{array}{c}\text { HS } \\
1 \_1 \_1\end{array}$ & $\begin{array}{c}\text { HS } \\
1 \_1 \_2\end{array}$ & $\begin{array}{c}\text { HS } \\
1 \_1 \_3\end{array}$ & $\begin{array}{c}\text { HS } \\
1 \_1 \_4\end{array}$ \\
\hline IACS NA & 0.4021 & 0.3648 & 0.2817 & 0.2474 \\
\hline ABS unres. & 0.4186 & 0.3832 & 0.2949 & 0.2617 \\
\hline DNV WW & 0.1548 & 0.1413 & 0.1057 & 0.0934 \\
\hline WALDEN & 0.2341 & 0.2148 & 0.1634 & 0.1454 \\
\hline
\end{tabular}

Table 6 Fatigue Damage due to Wave Scatter Data (2).

\begin{tabular}{|c|c|c|c|c|}
\hline $\begin{array}{c}\text { Wave } \\
\text { Scatter } \\
\text { Data }\end{array}$ & HS & HS & HS & HS \\
\hline IACS NA & 0.0962 & 0.0873 & 0.1937 & 0.1674 \\
\hline ABS unres. & 0.1189 & 0.1102 & 0.2138 & 0.1887 \\
\hline DNV WW & 0.0471 & 0.0443 & 0.0794 & 0.0706 \\
\hline WALDEN & 0.0876 & 0.0835 & 0.1306 & 0.1182 \\
\hline
\end{tabular}




\section{Wave spectrum}

Table 7 Fatigue Damage due to Wave Spectrum (1).

\begin{tabular}{|c|c|c|c|c|}
\hline $\begin{array}{c}\text { Wave } \\
\text { Spectrum }\end{array}$ & $\begin{array}{c}\text { HS } \\
1 \_1 \_1\end{array}$ & $\begin{array}{c}\mathrm{HS} \\
1 \_1 \_2\end{array}$ & $\begin{array}{c}\text { HS } \\
1 \_1 \_3\end{array}$ & $\begin{array}{c}\text { HS } \\
1 \_1 \_4\end{array}$ \\
\hline P-M & 0.4021 & 0.3648 & 0.2817 & 0.2474 \\
\hline JONSWAP & 0.4714 & 0.4228 & 0.3327 & 0.2882 \\
\hline
\end{tabular}

Table 8 Fatigue Damage due to Wave Spectrum (2).

\begin{tabular}{|c|c|c|c|c|}
\hline $\begin{array}{c}\text { Wave } \\
\text { Spectrum }\end{array}$ & HS & HS & HS & HS \\
\hline P-M & 0.0962 & 0.0873 & 2_1_3 & 2_1_4 \\
\hline JONSWAP & 0.0913 & 0.0817 & 0.2110 & 0.1802 \\
\hline
\end{tabular}

\section{Rainflow bandwidth effect}

Table 9 Fatigue Damage due to application of bandwidth effect (1).

\begin{tabular}{|c|c|c|c|c|}
\hline $\begin{array}{c}\text { Bandwidth } \\
\text { Effect }\end{array}$ & $\begin{array}{c}\text { HS } \\
1 \_1\end{array}$ & $\begin{array}{c}\text { HS } \\
1 \_1 \_2\end{array}$ & $\begin{array}{c}\text { HS } \\
1 \_-3\end{array}$ & $\begin{array}{c}\text { HS } \\
\text { 1_- } 4\end{array}$ \\
\hline Applied & 0.4021 & 0.3648 & 0.2817 & 0.2474 \\
\hline $\begin{array}{c}\text { Non- } \\
\text { applied }\end{array}$ & 0.4705 & 0.4268 & 0.3324 & 0.2919 \\
\hline
\end{tabular}

Table 10 Fatigue Damage due to application of bandwidth effect (2).

\begin{tabular}{|c|c|c|c|c|}
\hline $\begin{array}{l}\text { Bandwidth } \\
\text { Effect }\end{array}$ & 2_1_1 & $\begin{array}{c}\text { HS } \\
2 \_1 \_2\end{array}$ & $\begin{array}{c}\mathrm{HS} \\
2 \_1 \_3\end{array}$ & $\begin{array}{c}\mathrm{HS} \\
2 \_1 \_4\end{array}$ \\
\hline Applied & 0.0962 & 0.0873 & 0.1937 & 0.1674 \\
\hline $\begin{array}{l}\text { Non- } \\
\text { applied }\end{array}$ & 0.1203 & 0.1091 & 0.2402 & 0.2076 \\
\hline
\end{tabular}

\section{CONCLUSIONS}

In this paper, the parametric study was performed considering effects of the variables which are S-N curve data, wave scatter data, wave spectrum and bandwidth correction factor. The results are summarized as follows.(Table 11)

The parametric study based on the spectral fatigue analysis is hard to perform, because the spectral fatigue analysis has complex and difficult processes. The results of this paper contribute to resolve this problem.
The basic research for understanding effects of these variables to the fatigue damage was established in this paper. We are able to use these results to determine the design variables in the spectral fatigue analysis for the reference. And the results enhance the understanding about the procedure of the spectral fatigue analysis where these variables were used in.

Table 11 Results of Parametric Study.

\begin{tabular}{|c|c|c|c|c|}
\hline $\begin{array}{c}\text { S-N } \\
\text { Curve }\end{array}$ & $\begin{array}{c}\text { Wave Scatter } \\
\text { Data }\end{array}$ & $\begin{array}{c}\text { Wave } \\
\text { Spectrum }\end{array}$ & $\begin{array}{c}\text { Rainflow } \\
\text { Bandwidth } \\
\text { Effect }\end{array}$ & $\begin{array}{c}\text { D } \\
{[\%]}\end{array}$ \\
\hline DNV US-I & IACS NA & P-M & Applied & 100 \\
\hline DNV US-III & IACS NA & P-M & Applied & 4.1 \\
\hline ABS C & IACS NA & P-M & Applied & 15.3 \\
\hline ABS E & IACS NA & P-M & Applied & 158.5 \\
\hline DNV US-I & ABS unres. & P-M & Applied & 110.4 \\
\hline DNV US-I & DNV WW & P-M & Applied & 41.3 \\
\hline DNV US-I & WALDEN & P-M & Applied & 78.8 \\
\hline DNV US-I & IACS NA & JS & Applied & 110.3 \\
\hline DNV US-I & IACS NA & P-M & Non-Applied & 120.9 \\
\hline
\end{tabular}

\section{ACKNOWLEDGEMENTS}

This research was supported by Samsung Heavy Industries co., Ltd.

\section{REFERENCES}

DNV, 2008. Fatigue assessment of ship structures. DNV classification notes No.30.7, Det Norske Veritas, Norway.

ABS, 2006. Spectral-based fatigue analysis for floationg production, storage and offloading (FPSO) systems. ABS guidance note, American Bureau of Shipping, USA

Lloyd, 2002. Fatigue Design Assessment, Level 3 Guidance on direct calculations. Lloyd's Register, UK.

KR, 2010. Guidance for the Fatigue Strength Assessment of Ship Structures. Rules for classification of steel ships, Korean Resister of Shipping, Korea.

Miner, M.A, 1945. Cumulative damage in fatigue, Journal of Applied Mechanics. 12, pp. A159-164.

A. Almar-Naess, 1985. FATIGUE HANDBOOK. Tapir publication, Trondheim, Norway. 